\title{
Werknemers wensen bij verzuim een prominentere rol van bedrijfsarts én huisarts
}

\author{
F.M.M. van den Heuvel • R. Steenbeek • P.C. Buijs
}

Samenvatting De zorg verleend door bedrijfsarts en huisarts is tot nu toe weinig onderzocht vanuit het perspectief van de betrokken werknemers (patiënten) zelf. Dit onderzoek biedt inzicht in hoe werknemers aankijken tegen de betrokkenheid van hun bedrijfsarts én hun huisarts bij sociaal-medische begeleiding. Daartoe is in 2004 een vragenlijstonderzoek uitgevoerd onder 2410 verzuimende werknemers. Uit dit onderzoek komt naar voren dat verzuimende werknemers meestal te maken hebben met zowel de bedrijfsarts als de huisarts. Ze zien de medisch specialist feitelijk als hun belangrijkste behandelaar, maar hebben daarentegen het liefst te maken met hun huisarts of bedrijfsarts. Ze vinden vertrouwen in de bedrijfsarts én in de huisarts het belangrijkst, hoewel ze de huisarts op tal van punten positiever beoordelen dan de bedrijfsarts. Meestal weten ze niet of hun bedrijfsarts en huisarts onderling contact hebben. Ze hebben er meestal geen probleem mee als hun bedrijfsarts en huisarts toegang krijgen tot hun elektronisch patiëntendossier, mits ze daarvoor toestemming hebben gegeven.

Conclusie: werknemers (patiënten) willen bij verzuim een prominentere rol van zowel hun huisarts als bedrijfsarts dan nu het geval is.

Keywords werknemers · huisarts - verzuim - prioriteiten . vertrouwen $\cdot$ onafhankelijkheid $\cdot$ gegevens uitwisseling

F.M.M. van den Heuvel $(\bowtie)$

PersonaliaDrs. Floor van den Heuvel (psycholoog), dr. Romy Steenbeek (gedragswetenschapper), en dr. Peter Buijs (bedrijfsarts/ex-huisarts) zijn alle drie werkzaam als onderzoeker bij TNO Kwaliteit van Leven | Arbeid te Hoofddorp.CorrespondentieadresTNO Kwaliteit van Leven Arbeid, t.a.v. Drs. F. van den Heuvel (team SMB), Postbus 718, 2130 AS Hoofddorp. E-mail: floor.vandenheuvel@.tno.nl.
1. Verzuimende werknemers hebben meestal te maken met zowel de bedrijfsarts als huisarts.

2. Ze zien de medisch specialist als de belangrijkste behandelaar.

3. Ze hebben daarentegen het liefst te maken met hun bedrijfsarts of huisarts.

4. Ze vinden het vertrouwen in de bedrijfsarts en de huisarts het belangrijkst.

5. Ze beoordelen de huisarts op tal van punten positiever dan de bedrijfsarts.

6. Ze weten meestal niet of hun bedrijfsarts en huisarts onderling contact hebben.

7. Ze hebben er meestal geen probleem mee als beide artsen toegang krijgen tot hun elektronisch patiëntendossier, mits ze daarvoor toestemming geven.

Als werknemers serieuze gezondheidsproblemen krijgen, dan komen zij meestal in contact met hun bedrijfsarts én hun behandelend arts (huisarts en/of medisch specialist). Al jaren worden knelpunten geconstateerd in de relatie arbozorg-curatieve gezondheidszorg, zoals gebrekkige samenwerking/afstemming tussen bedrijfsartsen en huisartsen ${ }^{1-4}$ en de onduidelijke positie van de bedrijfsarts, althans in de ogen van behandelend artsen. ${ }^{1,5}$ Over hoe werknemers aankijken tegen hun bedrijfsarts en behandelend arts bij sociaal-medische begeleiding, is veel minder bekend, terwijl de inspanningen van deze artsen juist voor hen bedoeld zijn, en ze steeds actiever betrokken worden bij het oplossen van hun gezondheidsproblemen, vooral sinds de Wet verbetering poortwachter werd ingevoerd (2003). Daarom is het des te belangrijker om meer te weten over hoe werknemers aankijken tegen hun bedrijfsarts en hun huisarts. Uit diverse onderzoeken blijkt, dat werknemers met gezondheidsklachten zich tot beide artsen wenden; vóór 
de ziekmelding richten zij zich zelfs vaker tot de huisarts. ${ }^{6,7}$ Bovendien is een vergelijking tussen deze artsen aantrekkelijk, omdat het koppel huisarts-bedrijfsarts vaak als de spil wordt beschouwd om tot betere arboen curatieve zorgverlening te komen ${ }^{8}$.

In 2004 startten het Breed Platform Verzekerden en Werk (BPV\&W), de Nederlandse Federatie van Kankerpatiëntenverenigingen (NFK) en de Stichting Pandora, samen met TNO Arbeid het project 'Ziek en mondig', met als hoofddoel: versterking van de positie van werknemers vanaf het moment dat zij problemen met hun gezondheid krijgen. TNO heeft binnen dat project onderzocht hoe verzuimende werknemers aankijken tegen de bedrijfsarts, in vergelijking met de huisarts. Centrale onderzoeksvragen daarbij zijn:

1. Hoe zien werknemers beide artsen?

2. Wat vinden zij belangrijk in hun relatie met hen?

3. Hoe oordelen zij over beide artsen?

4. Wat weten werknemers van hun onderlinge contacten?

\section{Methode \\ Onderzoekspopulatie}

UWV heeft 5800 verzuimende werknemers geselecteerd, representatief naar leeftijd en geslacht. Driekwart verzuimde op dat moment 13 weken of langer. Deze groep is ook representatief wat betreft de branche waarin men werkzaam is. Een kwart van de steekproef betreft werknemers die 3-12 weken verzuimden. Aangezien dit om te vroege aanmeldingen bij UWV gaat, is deze steekproef niet representatief voor de branche waarin men werkzaam is.

\section{De vragenlijst}

In november 2004 ontvingen 5800 werknemers een door TNO ontwikkelde vragenlijst met een algemeen gedeelte, een verzuimdeel en een deel over de kijk op de bedrijfsarts en de huisarts. Het algemene deel bevatte met name vragen over demografische factoren. Het verzuimdeel bevatte onder andere vragen over verzuimduur, gezondheidsklachten, contacten vanwege verzuim, inbreng van de werknemer, werkaanpassingen in relatie tot herstel en terugkeer naar werk, en BEDRIJFSARTS, betrokken behandelaars. Het deel over de relatie met de bedrijfsarts en huisarts bevatte onder andere vragen naar het oordeel over hun toegankelijkheid, houding, vertrouwen in en communicatie, met hen, kennis over gezondheid en werk, intentie hen te bezoeken, en tevredenheid over beide $\operatorname{artsen}^{9,10}$. Deze vragen hadden een Likertschaal, waarbij 1 'helemaal niet mee eens' betekent en 5 'helemaal mee eens'.

Analyses

Bij de analyses zijn percentages en gemiddelde schaalscores berekend. Om subgroepen met elkaar te kunnen vergelijken, zijn gepaarde $t$-toetsen en デ2-toetsen uitgevoerd. Om na te gaan of verschillen statistisch significant en relevant zijn, zijn $p$-waarden en $d$-waarden berekend. Hiervan wordt alleen melding gemaakt als ze significant $(p<0,05)$ én relevant $\left(d \geq 0,02\right.$, effect size $\left.{ }^{11}\right)$ zijn.

\section{Resultaten}

Kenmerken van de respondenten

Van de 5800 verstuurde vragenlijsten kwamen er 2410 ingevuld terug (respons $42 \%$ ). Tabel 1 vermeldt de persoonskenmerken van de respondenten. De gemiddelde leeftijd is 44 jaar, $43 \%$ is man en $57 \%$ verzuimt $13-52$ weken. De meeste werknemers (32\%) hebben als hoogste opleiding havo/vwo/mbo en zijn werkzaam in de gezondheidszorg $(23 \%)$, een ambtelijke functie $(18 \%)$ of een administratieve functie (14\%). Maar liefst $83 \%$ zegt een chronische aandoening of ziekte te hebben: van het bewegingsapparaat $(35 \%)$, een psychische aandoening $(22 \%)$ of een andere chronische aandoening $(26 \%)$.

Contacten met bedrijfsarts en huisarts

Uit tabel 2 blijkt dat verreweg de meeste werknemers gedurende hun verzuim ten minste één keer contact hebben gehad met de bedrijfsarts $(92 \%)$ en de huisarts $(89 \%)$. Ze hadden vaker contact met de bedrijfsarts dan met de huisarts $(t=9,698 ; d f=2112 ; p=0,000$; $d=-0,273)$.

De belangrijkste behandelaar tijdens verzuim

In tabel 3 staat wie voor verzuimende werknemers feitelijk de belangrijkste behandelaar is (geweest). Voor de meeste is dat de specialist (29\%), gevolgd door de bewegingstherapeut $(18 \%)$, huisarts $(17 \%)$, psycholoog $(13 \%)$, bedrijfsarts $(11 \%)$ en (bedrijfs)maatschappelijk werker (4\%); $4 \%$ geeft aan geen behandelaar te hebben (gehad). Op de vraag met wie werknemers het liefst te maken hebben tijdens hun verzuim (zie ook tabel 3) antwoordden de meeste de huisarts $(36 \%)$ of de bedrijfsarts $(34 \%)$; slechts $12 \%$ koos de specialist. Verder blijkt dat werknemers die de huisarts hun belangrijkste 
Tabel 1 Persoonskenmerken van verzuimende werknemers

Totaal aantal zieke werknemers $(\mathrm{n}=2410)$

\begin{tabular}{|c|c|c|}
\hline \multirow[t]{2}{*}{ Geslacht } & $\operatorname{man}$ & $43 \%$ \\
\hline & vrouw & $57 \%$ \\
\hline \multirow[t]{5}{*}{ Opleiding } & lager onderwijs & $8 \%$ \\
\hline & lbo of vbo & $22 \%$ \\
\hline & mulo, mavo & $16 \%$ \\
\hline & havo, vwo, mbo & $32 \%$ \\
\hline & hbo, universiteit & $22 \%$ \\
\hline \multirow[t]{10}{*}{$\begin{array}{l}\text { Beroep of } \\
\text { functie }\end{array}$} & $\begin{array}{r}\text { ambtelijke } \\
\text { beroepen }\end{array}$ & $18 \%$ \\
\hline & transportberoep & $4 \%$ \\
\hline & administratieve & $14 \%$ \\
\hline & commerciële & $8 \%$ \\
\hline & dienstverlenend & $11 \%$ \\
\hline & gezondheidszorg & $23 \%$ \\
\hline & $\begin{array}{r}\text { leerkrachten, } \\
\text { docent }\end{array}$ & $8 \%$ \\
\hline & vakspecialist & $6 \%$ \\
\hline & $\begin{array}{r}\text { agrarische } \\
\text { beroepen }\end{array}$ & $2 \%$ \\
\hline & overig & $6 \%$ \\
\hline \multirow[t]{2}{*}{ Verzuimduur } & $<13$ weken & $43 \%$ \\
\hline & 13-52 weken & $57 \%$ \\
\hline \multirow{4}{*}{$\begin{array}{l}\text { Type } \\
\text { chronische } \\
\text { aandoening }\end{array}$} & bewegingsapparaat & $35 \%$ \\
\hline & psychisch & $22 \%$ \\
\hline & overig & $26 \%$ \\
\hline & geen & $17 \%$ \\
\hline
\end{tabular}

Tabel 2 Aantal contacten met de bedrijfsarts en de huisarts in verband met verzuim

\begin{tabular}{lrrr}
\hline & & $\begin{array}{r}\text { Bedrijfsarts } \\
(\mathrm{n}=2226)\end{array}$ & $\begin{array}{r}\text { Huisarts } \\
(\mathrm{n}=2226)\end{array}$ \\
\hline $\begin{array}{l}\text { Frequentie van het } \\
\text { contact }(\%)\end{array}$ & 0 keer & $8 \%$ & $11 \%$ \\
& $\begin{array}{r}1 \text { keer } \\
2 \text { keer of } \\
\text { meer }\end{array}$ & $80 \%$ & $65 \%$ \\
\hline
\end{tabular}

behandelaar vonden (17\%), bij verzuim ook het liefst te maken hadden met de huisarts (82\%; tabel 3). Wie de bedrijfsarts het belangrijkste vond (11\%), had ook bij verzuim het liefst te maken met de bedrijfsarts (84\%). Diezelfde voorkeur geldt voor de (bedrijfs)maatschappelijk werker, psycholoog, bewegingstherapeut en medisch specialist, al heeft $23-30 \%$ van hen het liefst met de bedrijfsarts te maken, en 20-29\% met de huisarts. Die voorkeur komt nog sterker naar voren bij verzuimende werknemers die geen behandelaar hebben (gehad). Van hen heeft $82 \%$ het liefst te maken met de bedrijfsarts of huisarts.

Bijdrage van bedrijfsarts en huisarts aan herstel en reïntegratie

In tabel 4 staat weergegeven welke bijdrage werknemers wensen van hun bedrijfsarts en huisarts, en of dit overeenkomt met de door hen ervaren realiteit: $80 \%$ wenst een positieve bijdrage van de bedrijfsarts, terwijl $65 \%$ aangeeft daadwerkelijk zo'n positieve bijdrage te ontvangen. En 74\% van de werknemers wenst een positieve bijdrage van de huisarts, terwijl $60 \%$ aangeeft daadwerkelijk zo'n positieve bijdrage te ontvangen. De gewenste bijdrage van de bedrijfsarts en de huisarts is hoger dan de daadwerkelijke bijdrage $(t=-16,333 ; d f=1562 ; p=0,000$; $d=0,439$ respectievelijk $t=-15,690 ; d f=1531$; $p=0,000 ; d=0,364)$.

\section{Prioriteiten van werknemers}

Aan verzuimende werknemers is gevraagd een zevental relevante thema's in relatie tot de bedrijfsarts en de huisarts te prioriteren (tabel 5). Voor de bedrijfsarts zijn dat vertrouwen $(69 \%)$, kennis over gezondheid en werk $(68 \%)$ en goede communicatie met deze arts $(67 \%)$, gevolgd door 'onafhankelijkheid' $(62 \%)$. Ook ten aanzien van de huisarts vinden de meeste werknemers vertrouwen het belangrijkst (81\%), gevolgd door 'onafhankelijkheid' (77\%) en goede communicatie met de huisarts (74\%). Daarentegen hechten werknemers het minst aan informatie over taken en bevoegdheden van zowel bedrijfsartsen als huisartsen.

Werknemers vinden vertrouwen in de huisarts nog belangrijker dan vertrouwen in de bedrijfsarts $(t=-10,725 ; d f=2257 ; p=0,000 ; d=0,278)$. Ditzelfde geldt voor onafhankelijkheid $(t=-13,815$; $d f=2238$; $p=0,000 ; d=0,360)$ en geneigdheid om deze artsen te bezoeken bij gezondheidsproblemen $(t=-17,528$; $d f=2248 ; p=0,000 ; d=0,437)$.

\section{Oordeel over bedrijfsarts en huisarts}

Over het algemeen zijn werknemers minder tevreden over hun bedrijfsarts dan over hun huisarts $(t=-21,819$; $d f=2227 ; p=0,000 ; d=0,650$; zie tabel 6$)$, en ook minder positief: ze hebben er minder vertrouwen in $(t=-35,185 ; d f=2220 ; p=0,000 ; d=1,014)$, zijn minder geneigd om bij gezondheidsproblemen de bedrijfsarts te bezoeken, $(t=-47,600 ; d f=2231$; $p<0,000 ; d=1,451)$, oordelen minder positief over diens houding $(t=-13,950 ; d f=2245 ; p=0,000$; $d=0,420)$, de communicatie $(t=-12,675 ; d f=2232$; 
Tabel 3 Verzuimende werknemers over hun behandelaren

\begin{tabular}{|c|c|c|c|c|c|c|c|c|}
\hline & \multicolumn{8}{|c|}{ Liefst te maken met $(\mathrm{n}=2203)$} \\
\hline & $\begin{array}{r}\text { Totaal } \\
\%\end{array}$ & $\begin{array}{r}\text { Bedrijfsarts } \\
\%\end{array}$ & $\begin{array}{r}\text { Huisarts } \\
\%\end{array}$ & $\begin{array}{r}\text { (B)MW } \\
\%\end{array}$ & $\begin{array}{r}\text { Psycholoog } \\
\%\end{array}$ & $\begin{array}{r}\text { Bewegingstherapeut } \\
\%\end{array}$ & $\begin{array}{r}\text { Specialist } \\
\%\end{array}$ & $\begin{array}{r}\text { Anders } \\
\%\end{array}$ \\
\hline $\begin{array}{l}\text { Belangrijkste } \\
\text { behandelaar }\end{array}$ & & & & & & & & \\
\hline is $(\mathrm{n}=2068)$ & & & & & & & & \\
\hline Totaal & & 34 & 36 & 2 & 7 & 7 & 12 & 2 \\
\hline Geen behandelaar & 4 & 37 & 45 & 0 & 0 & 0 & 18 & 0 \\
\hline Bedrijfsarts & 11 & 84 & 16 & 0 & 0 & 0 & 0 & 0 \\
\hline Huisarts & 17 & 18 & 82 & 0 & 0 & 0 & 0 & 0 \\
\hline (B)MW & 4 & 23 & 29 & 48 & 0 & 0 & 0 & 0 \\
\hline Psycholoog & 13 & 22 & 20 & 2 & 56 & 0 & 0 & 0 \\
\hline Bewegingstherapeut & 18 & 25 & 28 & 4 & 0 & 43 & 0 & 0 \\
\hline Specialist & 29 & 30 & 26 & 0 & 0 & 0 & 44 & 0 \\
\hline Anders & 4 & 25 & 29 & 2 & 0 & 0 & 0 & 44 \\
\hline
\end{tabular}

Tabel 4 Bijdragen van de bedrijfsarts en de huisarts aan herstel en/of terugkeer naar het werk

\begin{tabular}{|c|c|c|c|c|}
\hline & \multicolumn{2}{|c|}{ Gewenste bijdrage } & \multicolumn{2}{|c|}{ Daadwerkelijke bijdrage } \\
\hline & Positief & Negatief/geen & Positief & $\overline{\text { Negatief/gee }}$ \\
\hline Bijdrage van de bedrijfsarts & $80 \%$ & $20 \%$ & $65 \%$ & $35 \%$ \\
\hline Bijdrage van de huisarts & $74 \%$ & $26 \%$ & $60 \%$ & $40 \%$ \\
\hline
\end{tabular}

Tabel 5 Prioriteiten van verzuimende werknemers in relatie met de bedrijfsarts en de huisarts $(\mathrm{n}=2322)$

\begin{tabular}{lrr}
\hline Thema's & $\begin{array}{r}\text { Belangrijkst in relatie tot de bedrijfsarts } \\
(\%)\end{array}$ & $\begin{array}{r}\text { Belangrijkst in relatie tot de huisarts } \\
(\%)\end{array}$ \\
\hline Vertrouwen in de arts & $69 \%$ & $81 \%$ \\
Kennis arts over gezondheid en werk & $68 \%$ & $61 \%$ \\
Goede communicatie met de arts & $67 \%$ & $74 \%$ \\
De arts is onafhankelijk & $62 \%$ & $77 \%$ \\
Positieve houding van de arts & $59 \%$ & $66 \%$ \\
Intentie om arts te bezoeken & $40 \%$ & $61 \%$ \\
Informatie over taken en bevoegdheden van de & $30 \%$ & $36 \%$ \\
$\quad$ arts & & \\
\hline
\end{tabular}

$p=0,000 ; d=0,356)$ en zelfs over de kennis over gezondheid en werk $(t=-15,303 ; d f=2223$; $p=0,000 ; d=0,434)$. Over de onafhankelijkheid valt geen uitspraak te doen, omdat werknemers niet gevraagd is een oordeel te geven over de onafhankelijkheid van de huisarts, vanwege het ontbreken van een 'derden-belang' bij de huisarts. $^{12}$

Wel oordelen veel werknemers positief over de communicatie met de bedrijfsarts $(79 \%)$ en over de houding van de bedrijfsarts (65\%). Daarentegen geeft slechts $31 \%$ aan geneigd te zijn de bedrijfsarts te bezoeken bij gezondheidsproblemen. Ten slotte hebben werknemers die bij verzuim en terugkeer naar werk het liefst te maken hebben met de bedrijfsarts, meer vertrouwen in hem/haar dan in hun huisarts $(M=3,84$ respectievelijk $M=3,21$; $t=15,123 ; d f=1454 ; p=0,000 ; d=-0,794)$. Werknemers die het liefst te maken hebben met de huisarts, hebben juist meer vertrouwen in hem/haar dan in de bedrijfsarts $(M=4,33$ respectievelijk $M=4,16$; $t=-5,062 ; d f=1511 ; p=0,000 ; d=0,261)$.

\section{Contact tussen bedrijfsarts en huisarts}

Slechts $8 \%$ van de verzuimende werknemers zegt te weten dat de bedrijfsarts en huisarts contact hebben over hun gezondheidssituatie, en $21 \%$ weet dat de bedrijfsarts en huisarts het eens zijn over de behandeling (zie tabel 7).

Ten slotte vindt $94 \%$ het goed als de bedrijfsarts, huisarts en andere behandelaar(s) onderling contact hebben, 
Tabel 6 Verzuimende werknemers over de bedrijfsarts en de huisarts, van 1 (helemaal niet mee eens) tot 5 (helemaal mee eens). Hoe hoger de gemiddelde score, des te positiever het oordeel

\begin{tabular}{|c|c|c|c|c|c|c|c|c|}
\hline \multirow[b]{2}{*}{ Thema's } & \multicolumn{2}{|l|}{$\begin{array}{l}\text { Gemiddelde } \\
(\mathrm{n}=2221)\end{array}$} & \multicolumn{2}{|c|}{$\begin{array}{l}\text { (Helemaal) niet mee } \\
\text { eens }\end{array}$} & \multicolumn{2}{|l|}{ Neutraal } & \multicolumn{2}{|c|}{ (Helemaal) mee eens } \\
\hline & bedrijfsarts & huisarts & bedrijfsarts & huisarts & bedrijfsarts & huisarts & bedrijfsarts & huisarts \\
\hline Goede communicatie met de arts & 3,88 & 4,12 & $3 \%$ & $1 \%$ & $18 \%$ & $11 \%$ & $79 \%$ & $88 \%$ \\
\hline Positieve houding van de arts & 3,71 & 4,09 & $12 \%$ & $4 \%$ & $23 \%$ & $15 \%$ & $65 \%$ & $81 \%$ \\
\hline Tevredenheid over arts & 3,51 & 4,11 & $17 \%$ & $5 \%$ & $27 \%$ & $13 \%$ & $56 \%$ & $82 \%$ \\
\hline $\begin{array}{l}\text { Kennis arts over gezondheid en } \\
\text { werk }\end{array}$ & 3,47 & 3,82 & $12 \%$ & $5 \%$ & $33 \%$ & $24 \%$ & $55 \%$ & $71 \%$ \\
\hline Vertrouwen in de arts & 3,49 & 4,24 & $12 \%$ & $2 \%$ & $35 \%$ & $11 \%$ & $53 \%$ & $87 \%$ \\
\hline Intentie om arts te bezoeken & 2,95 & 4,14 & $35 \%$ & $2 \%$ & $34 \%$ & $12 \%$ & $31 \%$ & $86 \%$ \\
\hline
\end{tabular}

Tabel 7 Contact en gegevensuitwisseling tussen bedrijfsarts en behandelaar $(n=1600)$

\begin{tabular}{|c|c|c|}
\hline & $\mathrm{Ja}$ & $\begin{array}{r}\text { Nee/weet } \\
\text { niet }\end{array}$ \\
\hline $\begin{array}{l}\text { Mijn bedrijfsarts en huisarts hebben onderling contact over mijn gezondheidssituatie } 8 \% 92 \% \text { Mijn bedrijfsarts en } \\
\text { huisarts zijn het eens over mijn behandeling }\end{array}$ & $21 \%$ & $79 \%$ \\
\hline Mijn bedrijfsarts en behandelaar hebben onderling contact over mijn gezondheidssituatie & $21 \%$ & $79 \%$ \\
\hline Mijn bedrijfsarts en behandelaar zijn het eens over mijn behandeling & $31 \%$ & $69 \%$ \\
\hline Ik vind het goed als mijn huisarts, bedrijfsarts en behandelaar(s) contact hebben, mits ik hiervoor toestemming geef & $94 \%$ & $6 \%$ \\
\hline $\begin{array}{l}\text { Ik vind het goed als mijn huisarts, bedrijfsarts en behandelaar(s) toegang krijgen tot mijn elektronisch } \\
\text { patiëntendossier, mits ik hiervoor toestemming geef }\end{array}$ & $83 \%$ & $17 \%$ \\
\hline
\end{tabular}

mits ze daarvoor toestemming geven. Onder dezelfde voorwaarde vindt $83 \%$ het goed als de bedrijfsarts, huisarts en andere behandelaar(s) toegang krijgen tot hun elektronisch patiëntendossier.

\section{Conclusies en discussie}

Op grond van bovenstaande resultaten zijn de vier centrale onderzoeksvragen als volgt te beantwoorden.

Werknemers hebben bij verzuim liefst te maken met hun huisarts of bedrijfsarts

Veruit de meeste werknemers hebben bij verzuim contact gehad met hun bedrijfsarts én huisarts, echter vaker met de bedrijfsarts. De belangrijkste behandelaar bij verzuim blijkt, met aanzienlijke voorsprong, de medisch specialist te zijn. Een mogelijke verklaring hiervoor is, dat veel werknemers in dit onderzoek een chronische aandoening hebben en daarvoor waarschijnlijk onder specialistische behandeling zijn. Als het echter om de wenselijke positie gaat, hebben werknemers bij verzuim liever te maken met hun huisarts of bedrijfsarts dan met de medisch specialist. Deze voorkeur is sterk wanneer verzuimende werknemers de huisarts of bedrijfsarts beschouwen als belangrijkste feitelijke behandelaar: de overgrote meerderheid heeft dan ook het liefst te maken met hun huisarts respectievelijk bedrijfsarts. En van diegenen die de (bedrijfs)maatschappelijk werker, psycholoog, bewegingstherapeut of specialist als hun belangrijkste behandelaar zien, hebben weliswaar de meeste het liefst met die betreffende behandelaar te maken, maar geeft een substantiële minderheid ook dan de voorkeur aan de bedrijfsarts of huisarts. Pregnant is die voorkeur ook bij werknemers die geen behandelaar hebben (gehad) bij verzuim: driekwart van hen heeft het liefst te maken met de bedrijfsarts of huisarts. Bovendien vindt meer dan de helft van de verzuimende werknemers dat zowel hun bedrijfsarts als huisarts al een aanzienlijke, positieve bijdrage levert aan hun herstel en werkhervatting. Niettemin verlangen ze van beide artsen een nog grotere bijdrage. Geconcludeerd kan dan ook worden dat werknemers bij verzuim een aanzienlijk prominentere rol wensen van zowel de bedrijfsarts als de huisarts dan nu het geval is.

Werknemers vinden vertrouwen in bedrijfsarts en huisarts het belangrijkst

Gezien die gewenste prominentere rol is het belangrijk te weten aan welke aspecten van hun relatie met beide artsen werknemers veel waarde hechten. Wat de bedrijfsarts betreft: verzuimende werknemers vinden vertrouwen, deskundigheid en communicatie het belangrijkst, daarna pas onafhankelijkheid. Bij de huisarts wordt 
vertrouwen het hoogst aangeslagen - nog hoger dan bij de bedrijfsarts - gevolgd door onafhankelijkheid van en communicatie met de huisarts. Deze eerste plaats voor vertrouwen in de huisarts kan een uitdrukking zijn van het feit, dat de huisarts voor veel patiënten dé medische vertrouwenspersoon is, bij wie geen 'derden-belang' speelt ${ }^{12}$ en het medisch geheim vanouds gegarandeerd is. In dit licht moet wellicht ook gezien worden, dat voor werknemers de onafhankelijkheid van de huisarts kennelijk zwaarder weegt dan die van de bedrijfsarts. Niettemin is dit opmerkelijk, aangezien de bedrijfsartsen de laatste jaren juist op de bres staan voor hun professionele onafhankelijkheid, vanwege het veronderstelde belang van een onafhankelijk en professioneel oordeel voor hun werknemers (patiënten). ${ }^{13}$

De meeste werknemers vinden informatie over taken en bevoegdheden van beide artsen het minst belangrijk. Dat is zorgelijk, omdat uit ditzelfde onderzoek blijkt ${ }^{14}$ dat werknemers weinig afweten van taken en bevoegdheden van de bedrijfsarts, en dat dit samenhangt met minder vertrouwen in deze arts, zodat hier een vicieuze cirkel dreigt.

Werknemers beoordelen de huisarts positiever dan de bedrijfsarts

$\mathrm{Nu}$ we weten wat verzuimende werknemers belangrijk vinden in relatie tot beide artsen, is hun 'ervaringsoordeel' over de praktijk interessant. Dan blijkt, dat zij op cruciale punten ontevredener zijn over de bedrijfsarts: ze hebben minder vertrouwen in de bedrijfsarts, zijn minder geneigd hem/haar te bezoeken bij gezondheidsproblemen, zijn negatiever over diens onafhankelijkheid en houding, communicatie, informatie over taken en bevoegdheden, en zelfs over diens kennis inzake gezondheid en werk. Dit laatste is opmerkelijk omdat bedrijfsartsen juist specialisten heten te zijn inzake de relatie arbeid en gezondheid. Voorts blijkt uit eerder onderzoek, dat veel bedrijfsartsen vinden, dat huisartsen juist onvoldoende afweten van bedrijfsgezondheidszorg en (recente) wetgeving op dit terrein, en eenderde van de huisartsen hen daarin bijvalt. ${ }^{1}$ Recent onderzoek bevestigt het bestaan van deze zogeheten 'blinde vlek voor werk' bij huisartsen. ${ }^{15}$ Wellicht is een verklaring voor dit minder positieve oordeel, dat werknemers het contact met de bedrijfsarts als minder vrijblijvend ervaren dan dat met hun huisarts. Toch moet ook hier niet al te somber tegenaan gekeken worden, gezien het op zich positieve oordeel van de meeste verzuimende werknemers over de communicatie met, en houding van de bedrijfsarts.
Werknemers onwetend over contact tussen huisarts en bedrijfsarts

Weinig werknemers kunnen aangeven of de bedrijfsarts en huisarts contact hebben over hun gezondheidssituatie en - nog belangrijker - of ze het onderling eens zijn over de behandeling. Onvoldoende afstemming tussen arboen curatieve zorg was uit onderzoek al langer bekend. Daarom heeft TNO in 2002 een Leidraad Afstemming huisarts-bedrijfsarts ontwikkeld voor de LHV en NVAB,${ }^{16}$ met actieve betrokkenheid van de werknemer (patiënt); met name via een communicatieformulier, dat zij na het geven van een informed consent overbrengen naar de andere arts. Blijkens dit onderzoek vinden de meeste werknemers het goed als de bedrijfsarts en behandelaar(s) onderling contact hebben over hun gezondheidssituatie, mits ze hiervoor toestemming geven. En, opmerkelijk is dat de meeste werknemers onder dezelfde condities er evenmin bezwaar tegen hebben dat de bedrijfsarts en behandelaar(s) toegang krijgen tot hun eventuele elektronisch patiëntendossier.

\section{Slotconclusie}

Voor het eerst is grootschalig onderzocht hoe werknemers (patiënten) aankijken tegen hun huisarts en bedrijfsarts bij sociaal-medische begeleiding. Daaruit komt een duidelijk beeld naar voren: voor verzuimende werknemers is de medisch specialist feitelijk de belangrijkste behandelaar, maar zij wensen een prominentere rol van zowel hun bedrijfsarts als hun huisarts. Vertrouwen, deskundigheid, goede communicatie en onafhankelijkheid vinden ze daarbij het belangrijkst. Op deze en andere punten slaan zij huisartsen hoger aan dan bedrijfsartsen. Of beide artsen onderling contact hebben, weten de meeste werknemers niet. Inzage in hun elektronisch patiëntendossier vinden de meeste werknemers geen probleem, mits met informed consent.

De resultaten uit dit onderzoek bieden aanknopingspunten voor beide medische professionals om hun zorgverlening aan de werknemer (patiënt) te verbeteren. Zo kunnen bedrijfsartsen bijvoorbeeld in contact met werknemers (meer) helderheid verschaffen over hun taken en bevoegdheden bij herstel en werkhervatting om zo het vertrouwen te vergroten. Huisartsen kunnen, tijdens het spreekuur bijvoorbeeld, in ieder geval aan werknemers vragen of het werk een rol speelt bij hun klachten. Maar ook werknemers dienen waar mogelijk zelf hun verantwoordelijkheid te nemen ten aanzien van hun herstel- en reïntegratieproces. De 'Reisgids voor de werknemer: wat en hoe bij ziekte en werk ${ }^{17}$ kan hen ondersteunen om die verantwoordelijkheid te nemen. 


\section{DANKWOORD}

Het onderzoek is gefinancierd door Stichting Instituut GAK, via het Breed Platform Verzekerden en Werk (BPV\&W). Tevens bedanken we UWV voor de medewerking bij het trekken van de steekproef uit haar bestand, de deelnemers van twee focusgroepen ter voorbereiding van de vragenlijst, en alle respondenten.

Belangenconflicten: geen gemeld

\section{Literatuur}

Amstel RJ van, Buijs PC. Voor verbetering vatbaar: de samenwerking tussen huisarts en bedrijfsarts bij sociaal-medische begeleiding. Hoofddorp: NIA-TNO, 1997.

Heideman JMC, Engels JA, Gulden van der JWJ. Knelpunten in de arbo-curatieve samenwerking tussen bedrijfsarts en huisarts: Wat staat een noodzakelijke gedragsverandering in de weg? TSG 2002; 3: 185-191.

Nauta N. Een vertrouwenskwestie? Over het samenwerken van huisartsen en bedrijfsartsen (proefschrift). Rotterdam: Optima Grafische Vormgeving, 2004.

Bakker RH. De samenwerking tussen huisarts en bedrijfsarts (proefschrift). Groningen: RUG, 2005.

Amstel RJ van, Buijs PC. Voor verbetering vatbaar (deel 2): medisch specialisten over hun samenwerking met bedrijfsartsen bij sociaal-medische begeleiding. Hoofddorp: TNO Arbeid, 2000.

Andrea H. Fatigue and mental health problems in the working population: descriptives and associations with consulting a physician (proefschrift). Maastricht: 2003.

Anema JR, Jettinghoff K, Houtman I, et al. Medical care of employees long-term sick listed due to mental health problems: a cohort study to describe and compare the care of the occupational physician an the general practitioner. J Occup Rehabil 2006; 16: 38-49.

Buijs PC (red). Samenwerking van bedrijfsarts en huisarts bij SMB van werknemers. Utrecht: LHV/NVAB, 1998.

Steenbeek R, Kool RB, Visser E, Putten DJ van. De juiste verwijzing: evaluatieonderzoek verwijsfunctie bedrijfsarts: eindmeting: stand van zaken een jaar na invoering. Hoofddorp: TNO Arbeid, 2004.

Verbeek J, Dijk F van, Rasanen K et al. Consumer satis-faction with occupational health services: should it be measured? Occup Environ Med 2001; 58: 272-278.

Cohen J. Statistical power analysis for the behavioural sciences. Hillsdale, NJ: Erlbaum, 1988.

Leenen HJJ. Gezondheidszorg en recht. Alphen a/d Rijn: Samsom, 1981.

Buijs PC. Gebrek aan arbocuratieve afstemming: Tijd-schr Bedrijfs Verzekeringsgeneeskd 2001; 9: 206-211.

Steenbeek R, Heuvel FMM van den, Buijs PC. Werknemers weten te weinig over hun rechten en hande-lingsmogelijkheden met betrekking tot de bedrijfsarts. Tijdschr Bedrijfs Verzekeringsgeneeskd (dit nummer).

Buijs PC, Weel ANH. Blinde vlek voor arbeid in de gezondheidszorg: buitenlandse remedies voor Neder-lands probleem? Eindverslag deel 1: Kennisverwerving

t.b.v. het ministerie van SZW. Hoofddorp: TNO Kwaliteit van Leven, 2005.

LHV\&NVAB. Leidraad voor huisarts en bedrijfsarts bij de sociaalmedische begeleiding van arbeidsverzuim. Anema $\mathrm{H}$, Buijs $\mathrm{P}$, Amstel R van, Putten D van. TNO Arbeid, 2002. In: Speciale gecombineerde uitgave van De Huisarts en TBV, maart 2002.

Breed Platform Verzekerden en Werk, de Nederlandse Federatie van Kankerpatiëntenverenigingen, Stichting Pandora. Reisgids voor de werknemer: wat en hoe bij ziekte en werk. Assen: Dekkerdrukwerken, 2005. 